\title{
Murilo Mendes na Itália: tradução e bilinguismo
}

\author{
Raphael Salomão Khéde \\ Professor assistente da UFF \\ raphaelsalomao@hotmail.com
}

Resumo: $O$ trabalho tem como objetivo apresentar a tradução de alguns poemas em italiano de Murilo Mendes, colocando em evidência o contexto no qual o poeta brasileiro entra em contato com a cultura italiana e utiliza o italiano como língua de seu último livro de poesia, Ipotesi, publicado postumamente, em 1977. Serão expostas a dificuldade de se traduzir poesia e a complexidade intrínseca ao bilinguismo: a adoção do italiano por parte do poeta, a partir do português, e a tradução para o português, partindo do italiano.

Palavras-chave: Murilo Mendes. Poesia. Bilinguismo. Tradução.

Abstract: Lo studio si propone di presentare la traduzione di alcune poesie in italiano di Murilo Mendes, mettendo in luce il contesto nel quale il poeta brasiliano entra in contatto con la cultura italiana e utilizza l'italiano come lingua del suo ultimo libro di poesia, Ipotesi, pubblicato postumo nel 1977. Saranno evidenziate la difficoltà di traduzione della poesia e la complessità intrinseca di questo caso di bilinguismo: l'adozione dell'italiano da parte del poeta, partendo dal protoghese, e la traduzione al portoghese, partendo dall'italiano.

Key words: Murilo Mendes. Poesia. Bilinguismo. Traduzione.

\section{Introdução: Murilo Mendes na Itália}

Entre 1952 e 1957, Murilo Mendes (1901-1975) transcorre sua primeira estadia na Europa, dando conferências na Holanda, na Bélgica e na França (em 1953 fez uma palestra sobre Jorge de Lima na Sorbonne). Em 1957, Murilo Mendes, por sua vez, chega a Roma e à Universidade La Sapienža, 
contratado como professor de Literatura Brasileira, sendo destinado a viver na cidade eterna por quase 20 anos, em sodalício com Ungaretti e tantos outros artistas, literatos e pintores do período, primeiro, em sua casa no Castro Pretorio e depois na de Via del Consolato, nas proximidades da Praça Navona.

Devemos lembrar ainda que o contato da cultura brasileira com a italiana já tinha precedentes nesse período. Em 1953 Sérgio Buarque de Holanda se transfere para Roma com a família, tendo sido contratado para dar um curso de Literatura e Cultura Brasileira na Universidade La Sapienæa, iniciando um intercâmbio cultural que durante muitos anos acabou por consolidar-se. Durante sua estadia em Roma de 1953 a 1955, Sérgio Buarque de Holanda, além de dar aulas na Sapienza, realizou importantes pesquisas nas maiores e mais antigas bibliotecas da cidade, em particular sobre o Descobrimento do Brasil e os mitos edênicos, publicando depois em São Paulo, em 1959, uma das suas obras mais importantes: Visão do Paraíso. Os motivos edênicos no Descobrimento e colonização do Brasil.

Com fama de católico praticante (a célebre conversão aconteceu em 1934, através do amigo Ismael Nery) ${ }^{1}$, catolicismo esse que seria fixado no volume Tempo e eternidade, de parceria com Jorge de Lima, Murilo chega à Itália ao lado de sua esposa, Maria da Saudade Cortesão, filha de Jaime Cortesão, grande historiador e líder do antifascismo português, exilado no Brasil durante as décadas de 1940 e 1950. Na Europa ele estreitará relações

1 Em Recordaçoes de Ismael Nery, publicado em 1996 com prefácio de Davi Arrigucci Jr., livro que reúne 17 artigos publicados originalmente em 1948 para o Estado de S. Paulo e para Letras e Artes, Murilo no final do último artigo escreve sobre essa sua experiência de contato com a fé cristã (MENDES, 1996, p. 152): "Conferi no mosteiro o que havia aprendido com Ismael Nery, amigo providencial: os elementos permanentes do catolicismo, o lastro de novidades que a tradição traz no seu bojo, as riquezas do Evangelho, o homem novo- homem voltado para o futuro, e que cresce para atingir a medida da estatura do Cristo. A morte do grande amigo com o qual eu realizara uma das mais altas experiências que nos é dado tentar - chegarmos à definitiva compreensão pelo silêncio mútuo-, a morte do grande amigo não me abateu: abriu-me uma vida de infinitas possibilidades, uma aventura de infindável trama. Em pouco tempo adivinhei que recebera o privilégio de contemplar, na face da morte de Ismael Nery, um reflexo transfigurado do próprio filho de Deus." A reconstrução da conversão e da fé católica no contexto cultural da época foi bem estudada por Castañon Guimarães (1993, pp. 36-50). 
com toda uma inteligentria modernista e democrática de escritores e poetas, alguns de vanguarda, outros não, como: Albert Camus, Jorge Guillén, René Char, Henri Michaux, além de pintores e artistas plásticos como René Magritte, Arp, Max Ernst, Alberto Magnelli.

Em Roma, Murilo não perde totalmente sua tão mencionada fé, mas desenvolve uma reação de pânico e de recusa, inicialmente, à Igreja de Roma. Negação esta que se estende também àquela língua "outra", a língua italiana, que o poeta, no início, não adota no momento de criar seus poemas, mas que depois se torna a língua de seu último livro de poesia, Ipotesi.

O primeiro livro a sair no "exílio" será Siciliana, homenagem à ilha da Itália que o tinha fascinado pela sua luz, cores e ruínas, e que acabou saindo em edição bilíngue na Itália em 1959, com prefácio do grande amigo italiano Giuseppe Ungaretti.

A sua casa torna-se local de reuniões de artistas, poetas e escritores (Rafael Alberti e Miguel Angel Asturias, Alberto Moravia e Elsa Morante, Ignazio Silone e Vinicius de Moraes, Haroldo e Augusto de Campos, Sábato Magaldi e Alexandre Eulálio, Ruggero Jacobbi), gente de cinema, críticos (além dos italianos, Antonio Candido e Gilda de Mello e Sousa) e sobretudo pintores, escultores e artistas plásticos.

\section{Murilo Mendes e Ungaretti: Convergência}

Em produções posteriores como Convergência, livro escrito entre 1963 e 1966, fazem-se mais constantes as referências à cultura italiana, como vemos nos "grafitos" para Paolo Uccello e para Borromini, ou nos "murilogramas" a Guido Cavalcanti, a Leopardi, a Ungaretti, entre outros. Convergência é o último livro de poesia publicado em vida por Murilo (em 1970 em São Paulo), 12 anos depois de Tempo espanhol (Lisboa, 1959). A obra é dividida em duas partes: Convergência e Sintaxe: sendo que Convergência se divide, por sua vez, em 
duas partes: a primeira, Grafitos, tem 35 poemas, a segunda, Murilogramas, 38. O segundo volume, Sintaxe, tem 71 poemas (COELHO, 1984, p.121):

\begin{abstract}
Os subtítulos, "Grafitos", "Murilogramas" e "Sintaxe" por si próprios exprimem a orientação dos poemas para a palavra, enquanto forma. "Grafitos" projeta a idéia de linha traçada em seus contornos essenciais; "Murilograma", o poeta -Murilo- e a palavra -grama-, como entidades indissolúveis, em que ser humano e palavra perdem sua individualidade; e "Sintaxe", o próprio processo de composição, pelo qual a linguagem se faz.
\end{abstract}

Característica evidente e recorrente em todos os setores do livro é a transgressão da norma linguística em prol de uma liberdade experimental, sendo Convergência um livro no qual, em toda a extensão do discurso poético muriliano, se apresenta o experimentalismo em sua mais exacerbada realização ${ }^{2}$. Estrangeirismo, plurissignificação das palavras (através de sua disposição, que convida para mais de uma possibilidade de leitura), presença de hífens, barras, neologismo, uso não corrente de prefixos ou sufixos, são alguns dos elementos de experimentação mais frequentes em toda a obra. $\mathrm{O}$ rigor do desenho geométrico indica exatamente a tendência da poesia em direção à "síntese" (a concisão e a linguagem fragmentada, como observaremos mais adiante, caracterizam praticamente todos os textos) e à "tortura da forma" (expressões usadas pelo poeta na entrevista citada em nota). Sinais gráficos como \&, ., /, =, + e - proliferam por todos os setores do livro ${ }^{3}$.

Murilograma a Ungaretti, escrito em Roma em 1965, é uma referência ao poema La pietà (1928) de Giuseppe Ungaretti (1888-1970) que está no volume Sentimento del tempo, cujo primeiro verso (Sono un nomo ferito) é citado no verso 3: "Uomo ferito" ir, prestes arando/para fundar o ser, próprio à palavra. Esse murilograma é constituído de 7 dísticos, sendo que 5 deles têm períodos

2 Em carta enviada de Roma no dia primeiro de dezembro de 1969 a Laís Corrêa Araújo (2000, p.196), Murilo se refere a Convergência como “ livro capital de minha nova linguagem”.

${ }^{3}$ Cf. GUIMARÃES, 1993, pp.71-72. 
somente com o verbo no infinitivo, sem a oração principal, como por exemplo no primeiro dístico: Conhecer os limites da linguagem/ Afrontando as palavras travestidas. O efeito criado é realmente o de uma dissonância rítmica: os "limites da linguagem", por ser a palavra "refratária" e "travestida", são concretizados pela ruptura rítmica, pelo andamento amelódico dos versos truncados, até chegarmos ao abstrato: A natureza, didascália informe,/Exaure-se, frente ao diagrama abstrato.

Quando "a natureza exaure-se", o "fogo-interno" alimenta a palavra, "nossa única herança e território", e nutre o silêncio-grito em Murilo (verso 12) assim como em Ungaretti (Ho popolato di nomi il silenæ̧io; Sono stanco di urlare senæa $\left.v o c e^{4}\right)$; o adjetivo "nossa" indica o mesmo questionamento por parte dos dois poetas frente aos "limites da linguagem" que é, ao mesmo tempo, a herança e o território dos dois. Por outro lado, esse murilograma parece dialogar também com o pequeno poema Commiato publicado no livro L'Allegria, cujos cinco versos finais referem o esforço do poeta em "escavar" o silêncio à procura da palavra, encontrando o abismo: Quando trovo/ in questo mio silenzio/ una parolal scavata è nella mia vital come un abisso ${ }^{5}$.

Ungaretti ocupou a cátedra de Língua e Literatura italiana da Faculdade de Filosofia, Ciências Humanas e Letras da Universidade de São Paulo entre 1936 e 1942. Prefaciou, como já mencionado, a edição bilíngue Siciliana de Murilo, que saiu na Itália em 1959, e, em 1961, traduziu poemas do poeta e amigo para uma antologia italiana em edição bilíngue intitulada Introducão à poesia de Murilo Mendes e, no mesmo ano de 1961, traduziu também os textos que compõem a pequena antologia Finestra del caos.

\section{Ipotesi}

\footnotetext{
${ }^{4}$ Respectivamente $10^{\circ}$ e $39^{\circ}$ (e último) versos da primeira estrofe (UNGARETTI, 2007, p.303).

${ }^{5}$ Versos 9-13 (_ p.189). 
Ipotesi foi escrito em italiano em 1968 e publicado postumamente em 1977. O livro é dividido em seis partes: I) Informazioni; II) Ipotesi; III) Epigrammi e altro; IV) Omaggi; V) Città; VI) IL Programma. A quarta seção de poemas, Omaggi, contém poemas que variam desde pequenas descrições de pintores como Morandi ou Magnelli até alusões biográficas ou intertextuais a poetas e homens de cultura de diferentes épocas, como o poeta Dino Campana ou o roteirista Cesare Zavattini. Sobre a aproximação, inclusive linguística com a Itália, Luciana Stegagno Picchio, amiga e curadora de sua obra completa, assim lembra os "anos italianos" do poeta (MENDES, 1994, p.1708):

\footnotetext{
Murilo que, então era "civis romanus" havia onze anos, tinha assistido, primeiro despreocupadamente, depois com divertida participação, ao alterar-se do seu registro linguístico. O contato quotidiano com a cultura e a expressão ítalo-romanesca a todos os níveis- os dois dedos de conversa com o porteiro de Via del Consolato, o jornal da manhã e o vespertino, o diálogo com gentes diversas, estudantes, colegas, contínuos da Universidade, tinham-lhe criado alma nova. Certas coisas, certos conceitos, não lhe ocorriam mais em português, mas em palavras ou frases italianas. Eram estilemas retalhados da atualidade jornalística, nexos adjetivo-substantivo petrificados, locuções verbais captadas na esgrima diária do exprimir-se e memorizadas tal qual, segmentos a repetir como citações; eram sons de ressonâncias inauditas e imprevistas na caixa harmônica do aloglota.
}

Nesse livro, que é exemplo, inclusive, de intertextualidade na obra do autor, existe outro poema dedicado a Ungaretti, no qual a pergunta sobre os "limites da linguagem" permanece a mesma do poema de Convergência, terminando o texto com a dúvida sobre o futuro da palavra: Esisterà domani/ la parola domani?. A angústia que o tempo (a memória) proporciona a Ungaretti parece se refletir nesse questionamento sobre a sobrevivência da palavra. $\mathrm{O}$ trocadilho reforça a indicação de que nem a mencionada fé católica de Murilo poderá socorrê-lo: o futuro, que para os cristãos representa a salvação, aqui é motivo de desconfiança.

A única forma de resgate aparece na coluna da direita, em caixa alta, através de dois elencos numericamente simétricos, divididos por um espaço branco e com um ponto final na conclusão do segundo elenco, representando uma homenagem a poetas amados, que experimentaram a crise e a catástrofe em suas criações (no que concerne suas visionárias e angustiadas renovações estilísticas): Mallarmé, Gongora e William Blake. 


\section{Conclusão: tradução do poema}

\section{UNGARETTI}

Il viaggiatore non ancora stanco

di aver girato il mondo con le sue varianti

fantasticando sulle galassie

(lontanissime oppure centro dell'uomo?

that is the question)

portando gli emblemi della memoria

gli occhi alessandrini

sotto il colbacco nero

dopo aver guardato ammirato urlato ovunque

si ferma tutta la notte e il giorno successivo

sulla dinamica delle parole

MALLARMÉ

GONGORA

WILLIAM BLAKE

MEMORIA

CRISI

CATASTROFE.

Esisterà domani

la parola domani? 
se detém a noite inteira

UNGARETTTI

e o dia seguinte

sobre a dinâmica das palavras

O viajante não ainda cansado

por ter rodado o mundo com suas variantes

MALLARMÉ

devaneando sobre as galáxias

(longínquas ou então centro do homem?

GONGORA

WILLIAM BLAKE

that is the question)

MEMÓRIA

levando os emblemas da memória

os olhos alexandrinos

embaixo do colbaque preto

depois de ter por toda parte olhado admirado gritado

CRISE

CATÁSTROFE.

Existirá amanhã

A palavra amanhã?

\section{Referências bibliográficas}

ARAÚJO, Laís Corrêa de. Murilo Mendes: ensaio crítico, antologia, correspondência. São Paulo: Perspectiva, 2000.

COELHO, Odette Penha. O Experimentalismo em Convergência. Letterature d'Americhe. Roma: Bulzoni, 1984.

GUIMARÃES, Júlio Castañon. Territórios/Conjunçoes: poesia e prosa críticas de Murilo Mendes. Rio de Janeiro: Imago, 1993.

MENDES, Murilo. Ipotesi. Roma: Guanda, 1977. . Poesia completa e prosa. Rio de Janeiro: Nova Aguilar, 1994. Recordações de Ismael Nery. São Paulo: Edusp, 1996.

UNGARETTI, Giuseppe. Vita, Poetica, Opere Scelte. Milano: Mondadori, 2007. 